\title{
Design audiovisual: Remixabilidade na obra de Saul Bass
}

\section{Sergio Nesteriuk}

Doutor e mestre em Comunicação e Semiótica pela PUC-SP. Atuou como videomaker e produtor artístico e cultural no MIS (Museu da Imagem e do Som) e na Fundação Memorial da América Latina. Foi diretor de educação da ABCA (Associação Brasileira de Cinema de Animação) e consultor de roteiro e dramaturgia do ANIMATV (SAv, ABEPECe MinC). Professor do PPG em Design da Universidade Anhembi Morumbi.

E-mail: nesteriuk@hotmail.com

\section{Marcio Rodriguez Taú}

Especialista em Design pelo Centro Universitário Senac. Mestre (profissional) em Animação por Computador pela Universitat Pompeu Fabra - Barcelona. Atuou como diretor de arte e vídeo designer na TV Globo (1997-2011). Professor do Curso de Graduação em Design de Games da Universidade Anhembi Morumbi, onde também é mestrando em Design.

E-mail:marciotau@gmail.com
Resumo: Esse artigo pretende identificar nas produções audiovisuais feitas por Saul Bass (1920-1996) para o cinema a lógica da remixabilidade (Manovich, 2005) e entender como as tecnologias digitais podem contribuir para a hibridização de elementos de diferentes mídias na linguagem audiovisual. A partir da análise dos créditos de abertura do filme Casino (Martin Scorsese, 1995) e da relação com estudos de Lev Manovich (2005; 2007; 2008), Lucia Santaella (2007) e Arlindo Machado (1997) pretende-se apontar como o remix foi potencializado com as tecnologias digitais de manipulação de sons e imagens.

Palavras-chave: Design audiovisual; Remixabilidade; Mídias digitais; Créditos de abertura; Saul Bass.

\section{Audiovisual design: Remixability in Saul Bass's work}

Abstract: This article aims to identify in the audiovisual productions made by Saul Bass (1920-1996) for the cinema the logic of remixability (Manovich, 2005) and understand how digital technologies can contribute to the hybridization of different media elements in audiovisual language. From the analysis of the open titles of the Casino (Martin Scorsese, 1995) and the relationship with the studies of Lev Manovich (2005; 2007; 2008), Lucia Santaella (2007) and Arlindo Machado (1997) is intended to point out how the remix was boosted by digital technologies of image and sound manipulation.

Keywords: Audiovisual design; Remixability; Digital media; Opening credits; Saul Bass. 


\section{Cinema e motion graphics}

Saul Bass (1920 - 1996) foi um dos precursores do uso de elementos gráficos em produções para o cinema, realizando diversas aberturas, que além de identificar o nome do filme e dos profissionais envolvidos naquela obra (atores, produtores, diretores, etc.), também apresentavam ao espectador uma síntese gráfica da película que estava começando, utilizando textos e elementos gráficos combinados com sons e imagens em movimento. Ao longo de sua carreira Bass presenciou uma grande transformação nas tecnologias de captação e edição audiovisual, o que pode ser percebido em seus diversos projetos.

Em uma de suas primeiras contribuições para o cinema, na abertura do filme The man with the golden arm (Otto Preminger, 1955) os elementos gráficos têm movimentos simples comparado aos padrões atuais (figura 1). Já na abertura do filme Casino (Martin Scorsese, 1995), os textos e imagens têm composições mais elaboradas, com várias camadas sobrepostas e com transparências distintas (figura 2).

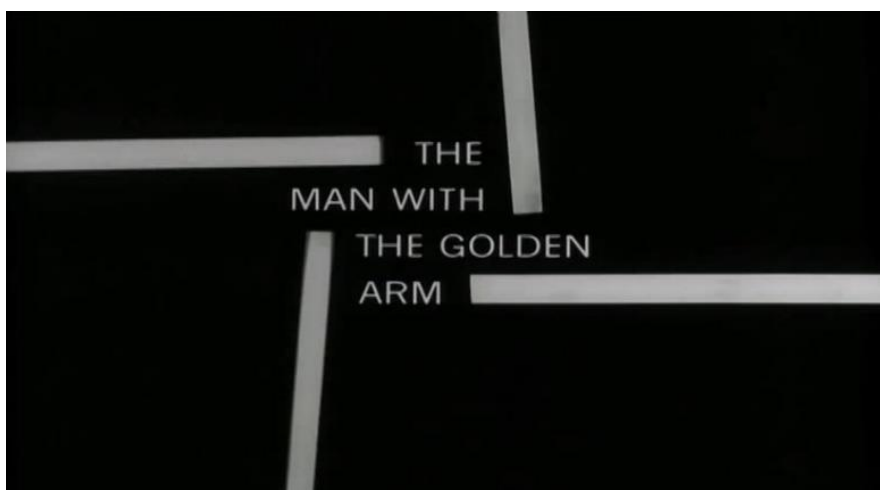

Figura 1: Fotograma com o texto do título do filme em composição com retângulos. Fonte: The man with the golden arm (1955), direção Otto Preminger.

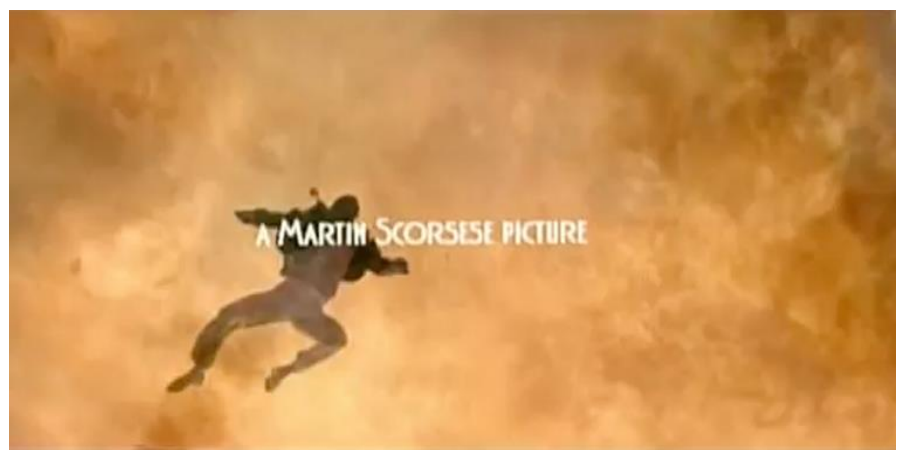

Figura 2: Imagem da personagem "voando" em composição com imagem de fogo e sobreposição de texto com o nome do diretor.

Fonte: Casino (1995), direção Martin Scorsese.

No intervalo de 40 anos que existe entre estes dois exemplos a tecnologia de composição de sons e imagens em movimento teve grande desenvolvimento, pois antes das ferramentas digitais, sobrepor tecnicamente texto em imagens em movimento não era uma tarefa simples. Segundo Manovich (2008) até o surgimento de ferramentas baseadas em softwares na década de 1990, combinar diferentes mídias baseadas em tempo era um processo demorado, muito caro ou em alguns casos simplesmente inviável.

Atualmente esse processo é muito mais rápido e acessível e os estúdios de design têm acesso a hardwares e softwares de alta performance literalmente em seus "desktops": animações 2D e 3D, pós produção e efeitos especiais agora são possíveis "in-house" (WOOLMAN, 2004). As possibilidades que os softwares de composição de imagens em movimento proporcionam influenciam diretamente 
o potencial criativo observado na linguagem das produções audiovisuais contemporâneas. Santaella (2007) aponta que uma das características mais importantes das estéticas digitais está na sua absorção e hibridização das estéticas tecnológicas anteriores. Neste sentido, estéticas precedentes não desaparecem quando surgem novas tecnologias, pelo contrário, vão se somando, complementando-se, interconectando-se.

Uma manifestação desse tipo pode ser identificada nas linguagens do cinema e da fotografia que, quando se tornaram digitais, incorporaram características de manipulação do vídeo. Machado (1997) aponta que diferentemente da imagem fotoquímica (fotografia e cinema), a imagem eletrônica é muito mais maleável e plástica; nela pode-se intervir indefinitivamente alterando suas formas, modificando seus valores cromáticos e desintegrando suas figuras, operando inclusive dentro de um eixo vertical de montagem - isto é, dentro do próprio quadro (frame) da imagem.

Softwares de edição e composição de imagens permitem "importar" e "exportar" mídias diversas para serem utilizadas em outros softwares. Por exemplo: é possível fazer uma ilustração vetorial em um aplicativo de desenho, editar diversas imagens em um software de manipulação de imagens, elaborar um modelo 3D em outro aplicativo, selecionar uma sequência de imagens em movimento em um programa de edição de vídeo, compor uma trilha sonora em um aplicativo de música, "importar" todos esses arquivos em um programa de composição de imagens para finalmente adicionar textos e elementos gráficos e animar todos os componentes e obter um resultado completamente diferente dos dados (arquivos) iniciais quando olhados separadamente, conforme podemos observar na figura abaixo.

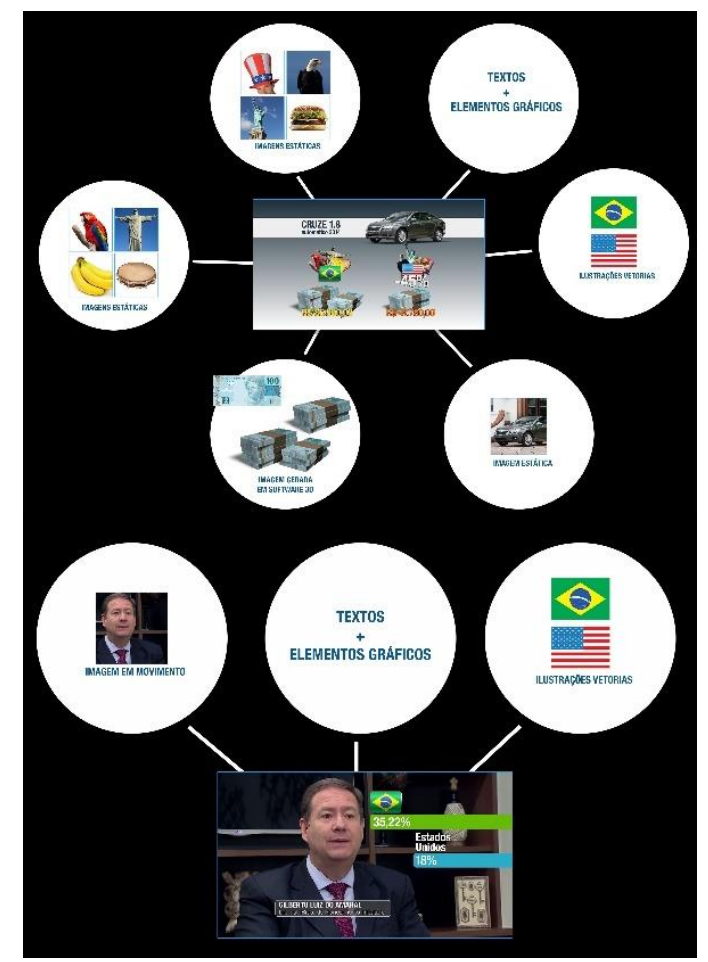

Figura 3: Infográfico animado criado para a matéria "Nota Fiscal" do programa de televisão AutoEsporte da TV Globo - novembro de 2014.

Fonte: Márcio Rodriguez Taú.

Nas palavras de Manovich:

A condição essencial que possibilita essa nova lógica do design e sua estética encontra-se na compatibilidade entre arquivos gerados por diferentes softwares. Em outras palavras, "importar", "exportar" e funções e comandos 
${ }^{1}$ Do original: The essential condition that enables this new design logic and the resulting aesthetics is compatibility between files generated by different programs. In other words, "import," "export" and related functions and commands of graphics, animation, video editing, compositing and modeling software are historically more important than the individual operations these programs offer.

\footnotetext{
${ }^{2}$ Oskar Fischinger, reconhecido por criar animações musicais abstratas, foi o responsável pelos efeitos especiais do filme Woman in the moon (Fritz Lang, 1929).
}

${ }^{3}$ Maurice Binder é mais conhecido por produzir a abertura para quatorze filmes da série (franquia) James Bond.

\footnotetext{
${ }^{4}$ O comércio de forma geral utiliza o termo "revelação digital" de forma equivocada. $\mathrm{Na}$ verdade, o serviço que estas empresas oferecem é o de imprimir um arquivo digital em papel fotográfico, isto é, não tem nenhuma relação com o processo de revelação fotoquímico.
}

relacionados a softwares de gráficos, animações, edições de vídeo, composição e modelagem são historicamente mais importantes que as operações individuais que esses programas oferecem (MANOVICH, 2008: 147). ${ }^{1}$

Esta possibilidade que o meio digital oferece de somar e interconectar diferentes conteúdos gera um novo tipo de mídia, que Manovich (2008) denomina de "mídia híbrida", na qual as linguagens anteriores diferentes se mesclam, trocando propriedades, criando novas estruturas e interagindo de maneira profunda, como ocorre, por exemplo, nos chamados motion graphics.

O termo em inglês motion graphics é utilizado comumente para identificar elementos gráficos animados em produções audiovisuais - mas isso não basta para estabelecer uma definição coerente do termo per se. Diversos elementos visuais quando em uma produção audiovisual podem ser entendidos como motion graphics: textos, formas geométricas, ilustrações, fotografias, imagens em movimento e objetos 3D, são alguns exemplos. Estes elementos podem ser utilizados separadamente e também juntos, ao mesmo tempo, interligados/sobrepostos. Assim, motion graphics não pode ser entendido como uma única disciplina e sim como uma convergência entre animação, ilustração, design gráfico, cinema narrativo, escultura e arquitetura, para citar algumas áreas atinentes (WOOLMAN, 2004).

Saul Bass junto com outros artistas como Oskar Fischinger ${ }^{2}$ (1900 - 1967), Norman McLaren (1914 - 1987) e Maurice Binder ${ }^{3}$ (1925-1991) são considerados precursores do motion graphics devido a suas produções audiovisuais com elementos gráficos em movimento. Mesmo antes de existir as ferramentas digitais "importar" e "exportar", estes profissionais já mesclavam diversas mídias de maneira analógica para criar seus projetos animados. Norman McLaren por exemplo, fazia ilustrações "quadro a quadro" diretamente na película para criar animações abstratas sincronizadas com música, nesse processo ele "importava" a ilustração para uma mídia de imagem em movimento, a película do filme. Da mesma forma, as primeiras aberturas de filmes feitas por Saul Bass na década de 1950 apresentavam características de uma mídia híbrida, quando incorporavam textos, elementos gráficos, ilustrações e imagens em movimento para obter um resultado diferente dos elementos iniciais olhados separadamente.

\section{Remixabilidade}

A paisagem visual contemporânea é repleta de imagens sintéticas ou captadas que não são mais "puras", as imagens estáticas ou em movimento sofrem diversos ajustes como alterações de cor, retoques digitais, acréscimo de elementos gráficos, distorções, sobreposições, fusões, etc. Vivemos cercados de imagens híbridas, que mesclam linguagens de várias mídias de maneira complexa, que formam uma nova mídia híbrida que tem como lógica a remixabilidade.

Neste sentido, Machado (1997) aponta que o registro efetuado pela câmera fotográfica nada mais é que uma espécie de matéria-prima que deverá posteriormente ser trabalhada e transformada por algoritmos de tratamento de imagem. Assim, a palavra "fotografia" não é mais a marca deixada pela luz em uma superfície fotossensível e sim um grande processo de edição. A maior parte das imagens produzidas hoje deixou de ser fotoquímica, o procedimento de revelação deixou de existir no processo digital ${ }^{4}$, e as câmeras fazem seus registros de maneira digital: as fotos são arquivos armazenados em um dispositivo de memória que posteriormente são transferidas para computadores para serem editadas, recortadas e manipuladas. 
Muitas manifestações culturais da contemporaneidade, como a música, a moda, o design e as artes são regidas por remixes, fusões, colagens ou misturas. Se o pós-modernismo definiu a década de 1980, o remix definitivamente domina a década de 2000 e provavelmente vai continuar presente na próxima década também (MANOVICH, 2007).

A tecnologia digital de manipulação de imagens tornou mais evidente as manifestações da remixabilidade, mas os procedimentos técnicos que regem essas imagens podem ser identificados desde o começo do século XX. Diamond (2003) afirma que a cultura remix "empresta" sua técnica de procedimentos de movimentos das vanguardas artísticas do modernismo tardio e do pósmodernismo, como apropriação, colagem, dadá, grafite, mail art, objetos manipulados, fotomontagem, pop arte, arte processual e rascunho de vídeo. A colagem pode, neste sentido, ser entendida como uma estética remix. Pablo Picasso (1881-1973) utilizou essa técnica em algumas de suas obras, como em Still life with chair caning (1912) em que literalmente utilizou um pedaço da cadeira como parte da pintura (figura 4).

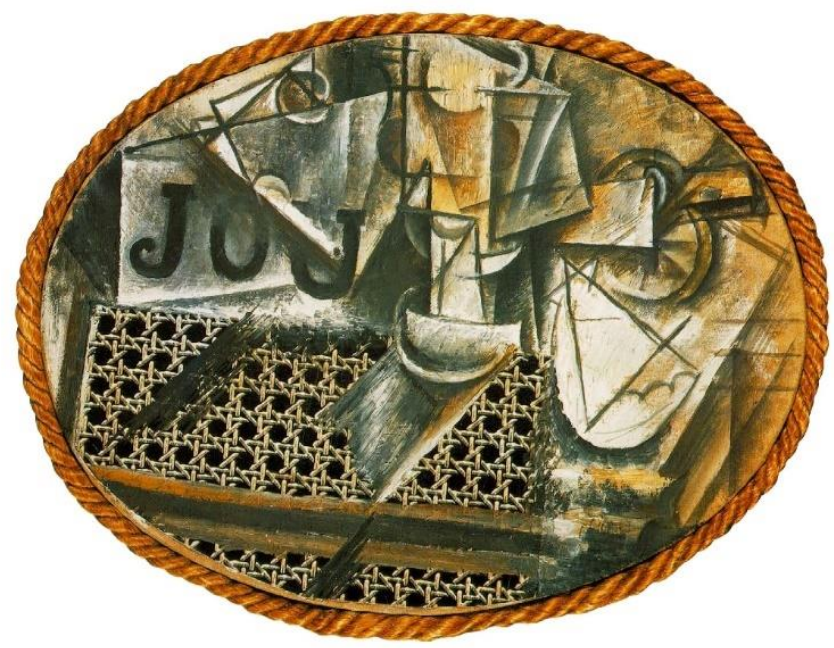

Figura 4: Pintura de Picasso com aplicação de pedaço de cadeira.

Os artistas dos movimentos dadaístas e surrealistas também fizeram uso desse tipo de procedimento em suas obras. No início do século XX, Marcel Duchamp (1887-1968) com seus ready-mades, ressignificava objetos ou imagens do cotidiano por meio de uma (re)contextualização ou simplesmente colocando um título ou legenda anexo à obra. Os artistas da Pop Art incorporaram a mercadoria, somando as imagens remixadas das mídias massivas em suas obras no final dos anos 1950 e início dos anos 1960. Outra referência para o remix é a apropriação da arte utilizada por artistas como Marcel Duchamp e Salvador Dalí (1904-1989) com suas Mona Lisas (figura 5).

${ }^{5}$ Equipamento que permite gravar áudio em múltiplas faixas simultâneas e sincronizadas.
Apesar de todas essas referências, o remix passa a ter um significado específico na música. Na década de 1970 surgiram os multitrack mixers ${ }^{5}$ que tornaram possível a manipulação de cada canal da música separadamente (vocais, bateria, guitarra, etc.), possibilitando o remix da canção, alterando o volume de determinado instrumento ou substituindo a voz do cantor, por exemplo. Já na década de 1980, o remix tornou-se a base da música pop eletrônica. “O pivô desse método estava no sampler, equipamento que armazena sons, parecido com um sintetizador, e permite reproduzir diferentes efeitos, de acordo com as configurações desejadas pelo DJ." (SANTAELLA, 2007: 267). Assim, os músicos passaram a samplear músicas já existentes criando novas versões musicais. 
${ }^{6}$ Do original: Generally speaking, remix culture can be defined as a global activity consisting of the creative and efficient exchange of information made possible by digital technologies. Remix, as discourse, is supported by the practice of cut/copy and paste. The concept of Remix that informs remix culture derives from the model of music remixes which were produced around the late 1960s and early 1970s in New York City, with roots in the music of Jamaica. During the first decade of the twenty-first century, Remix (the activity of taking samples from preexisting materials to combine them into new forms according to personal taste) has been ubiquitous in art, music and culture at large; it plays a vital role in mass communication, especially in new media.
De modo geral, a cultura remix pode ser definida como uma atividade global que consiste em um criativo e eficiente intercâmbio de informações amparado pelas tecnologias digitais. Remix, como discurso, tem como fundamento a técnica de cortar/copiar e colar. O conceito do remix, que molda a cultura remix, deriva de um modelo de música "remixada" que foi produzida no final da década de 1960 e começo da década de 1970 na cidade de Nova York, com raízes na música jamaicana. Durante a primeira década do século XXI, remix (a atividade de utilizar amostras de materiais pré-existentes pra combiná-las em novas formas de acordo com o gosto pessoal) tem sido onipresente na arte, na música e na cultura em geral; desempenha um papel vital na comunicação de massa, especialmente nas novas mídias. (NAVAS, 2010) ${ }^{6}$

Gradualmente o termo remix tornou-se mais e mais amplo: hoje qualquer reformulação de trabalho cultural já existente, sejam projetos visuais, softwares ou textos, são considerados remixes. Manovich (2005) entende que a maioria das culturas se desenvolve pelo empréstimo e reformulação de formas e estilos de outras culturas. Segundo o autor, a Roma Antiga "remixou" a Grécia Antiga, a Renascença "remixou" a Antiguidade, a arquitetura europeia do século XX "remixou" muitos períodos históricos incluindo a própria Renascença, e hoje designers gráficos e designers de moda juntos "remixam" inúmeras formas culturais e históricas, do mangá japonês à roupa tradicional indiana.
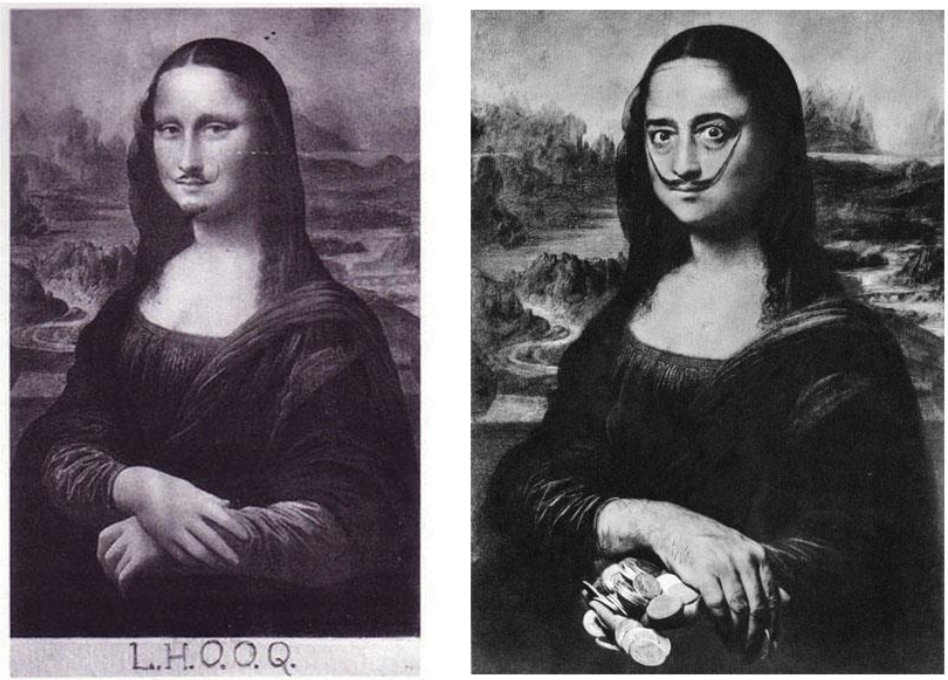

Figura 5: Obras com reproduções da Mona Lisa de Leonardo da Vinci (1452-1519) com interferências dos artistas. L.H.O.O.Q (1919) de Marcel Duchamp e Autorretrato como Mona Lisa (1954) de Salvador Dalí.

Os softwares de composição trabalham com diversos arquivos digitais (como vídeos, áudios, ilustrações e modelos 3D) que funcionam como módulos que podem ser acessados e manipulados de maneira individual sem perder suas características intrínsecas. A modularidade é, portanto, um princípio que potencializa a remixabilidade. As mídias analógicas já apresentavam essa característica modular, mas, o que aconteceu com a tecnologia digital foi que a modularização agora opera em nível estrutural: as imagens são quebradas em pixels, o design gráfico, o cinema e o vídeo são divididos em camadas (layers), o hipertexto modulariza os textos, linguagens e formatos digitais como HTML, Quicktime e MPEG modularizam documentos em hipermídia (MANOVICH, 2005). De maneira geral os conteúdos tendem a modularidade, por exemplo: as lojas online de música dividem os álbuns dos artistas em faixas que também podem ser comercializadas individualmente - o que antes era um objeto de cultura único, agora passa a ser acessado de maneira fragmentada. 
7 Motion blur é um efeito digital que simula a distorção de um objeto que se move rapidamente em relação à câmera, deixando um rastro de imagem.
8 A palavra em inglês "title" nesse contexto se refere ao trecho inicial de uma produção cinematográfica em que são inseridos o título do filme e os nomes dos profissionais envolvidos. Em português será utilizado o termo "crédito de abertura".

${ }^{9}$ Do original: [...] I began thinking about what to do at the beginning of a film. Obviously, the point of any title is to support the film. [...] My initial thoughts about what a title could do was to set mood and to prime the underlying core of the film's story; to express the story in some metaphorical way. I saw the title as a way of conditioning the audience, so that when the film actually began, viewers would already have an emotional resonance with it.
O "remix típico" combina conteúdos da mesma mídia (músicas remixadas é o resultado da mescla de trechos/módulos de diversos outras músicas) ou conteúdos de mídias diferentes (videoclipes misturam música com imagens em movimento, animações e videografismo). Outro aspecto apontado por Manovich (2008) é a "remixabilidade profunda" em que produções culturais não combinam somente conteúdos de várias mídias, mas remixam (reconfiguram) as técnicas fundamentais de cada mídia, os métodos de trabalho e as maneiras de representação e expressão de cada uma delas. Unidas em um ambiente digital comum, as linguagens do cinema, animação, efeitos especiais, design gráfico e tipologia (desenho das fontes) formam uma nova metalinguagem: híbrida e indissociável.

A remixabilidade profunda é, portanto, a transferência de uma técnica de uma mídia para outra, por exemplo: um texto que se move em um espaço 3D "empresta" as técnicas do cinema quando é representado em um ambiente com perspectiva e tem um posicionamento espacial em relação a uma câmera virtual, a aplicação de efeito de motion blur ${ }^{7}$ em elementos 3D gerados de maneira digital ou mesmo para simular desfoques de profundidade de campo em composições de imagens geradas digitalmente. Tais efeitos são comuns apenas às imagens captadas por câmeras, em que o tipo de lente e o movimento dos objetos determinam o aspecto da imagem, mas podem ser incorporados às imagens sintéticas geradas por computador.

Em cada um desses exemplos, a técnica que originalmente era associada a uma mídia particular - cinema, animação, computação gráfica fotorealista, tipografia, design gráfico - é agora aplicada a um tipo diferente de mídia. Hoje, um típico curta metragem ou uma sequência de um filme podem combinar muitos desses emparelhamentos dentro do mesmo quadro. O resultado é uma híbrida, intrincada, complexa e rica linguagem midiática - ou melhor, várias linguagens que compartilham a mesma lógica da remixabilidade profunda (MANOVICH, 2008: 112).

\section{As Abertura de filmes de Saul Bass}

Saul Bass foi pioneiro em criar pequenas animações utilizadas no início dos filmes para transmitir informações para o espectador de maneira textual, como o nome de atores, produtores, diretores e o próprio nome da obra. Além da característica informativa essa introdução/abertura preparava o espectador para as imagens seguintes, funcionando como uma espécie de prelúdio ou "pequeno filme" dentro do próprio filme que buscava dialogar, de maneira mais ou menos simbólica, diretamente com a narrativa da produção como um todo e seu "clima", como afirma o pioneiro:

"[...] eu comecei a pensar sobre o que fazer no início de um filme. Obviamente, o objetivo de qualquer crédito de abertura ${ }^{8}$ é apoiar a película. [...] Meus pensamentos iniciais sobre o que um crédito de abertura poderia fazer era definir o humor e preparar o núcleo fundamental da história do filme; para expressar a história de alguma maneira metafórica. Eu via o crédito de abertura como uma forma de condicionar o público, então quando o filme começasse, os espectadores já teriam uma ressonância emocional com ele" (HASKIN; BASS, 1996: 12). ${ }^{9}$

Antes de Saul Bass, os créditos que antecediam os filmes nada mais eram que uma série de nomes estáticos exibidos em sequência; a contribuição destes para a produção audiovisual era basicamente de cunho informativo. Nesse período, alguns filmes utilizavam apenas a tipologia para estabelecer uma relação visual elementar com a obra, como podemos observar, por exemplo, em King Kong 
(Merian C. Cooper e Ernest B. Schoedsack, 1933) e em The thing from another world (Christian Nyby e Howard Hawks, 1951) - figura 6.
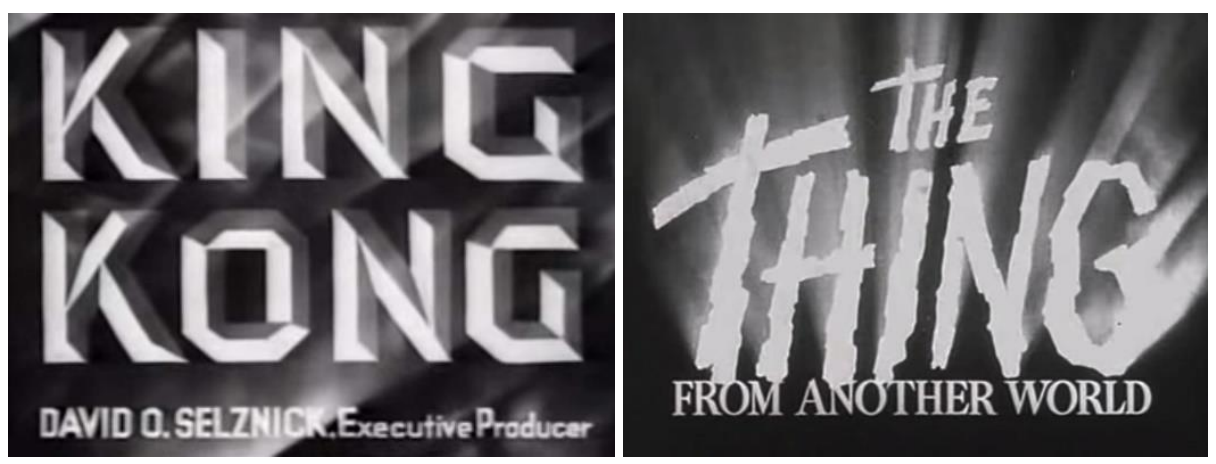

Figura 6: Fotograma com o título do filme e o nome do produtor executivo de King Kong (1933). À direita, fotograma com o título do filme The thing from another world (1951).

Bass viveu nos Estados Unidos e atuou em diversas áreas do design. Nasceu em Nova York e estudou no Art Students League e no Brooklyn College, onde teve como professor o designer Gyorgy Kepes, um dos fundadores da Staatliches Bauhaus - escola de vanguarda do design e uma das principais referências do Modernismo. Aos 26 anos mudou-se para Los Angeles, onde começou a trabalhar com publicidade direcionada para o entretenimento. Em 1954 iniciou sua parceria com o diretor de cinema Otto Preminger e criou a abertura do filme Carmen Jones, seu primeiro projeto para o cinema.

Em 1955, Bass criou um dos seus trabalhos mais reconhecidos, o pôster e a abertura do filme The man with the golden arm, também do diretor Otto Preminger com quem trabalhou em um total de onze produções cinematográficas. Além de Preminger outros diretores como Stanley Kubrick, Alfred Hitchcock e Martin Scorsese tiveram a participação recorrente de Saul Bass em suas obras.

Desde suas primeiras produções audiovisuais para o cinema pode-se identificar a lógica da remixabilidade em Bass: a própria natureza de seus trabalhos implica em um remix da imagem em movimento com a tipologia. Em sua primeira colaboração para o cinema, no filme Carmen Jones (figura 7), Bass combinou elementos de mídias diferentes para elaborar a animação de abertura. Os nomes do filme e dos profissionais envolvidos são sobrepostos em um fundo preto com uma chama vermelha no centro da tela e que possui um tratamento estilizado no qual somente seu contorno é percebido, adquirindo um aspecto de "ilustração em movimento". No interior do fogo há um desenho de uma rosa feita somente com linhas pretas. Nesse exemplo, pode-se identificar a combinação de ilustração, imagem em movimento e textos sobrepostos, elementos de mídias diferentes interagindo em um ambiente comum.

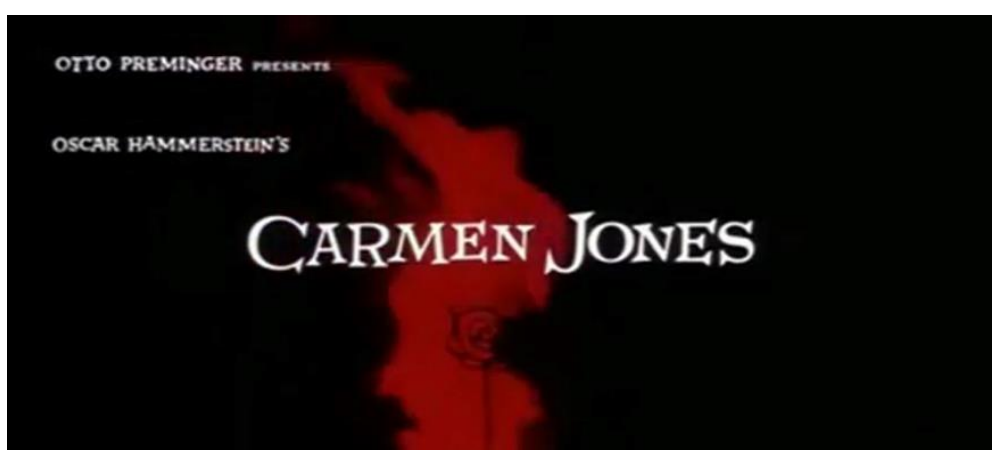

Figura 7: Fotograma o título do filme sobreposto a uma chama vermel ha com um desenho de uma rosa.

Fonte: Carmen Jones (1954), direção de Otto Preminger. 
A lógica da remixabilidade é muito evidente em toda a produção de Saul Bass para o cinema, e pode-se perceber que os avanços tecnológicos de manipulação de imagens contribuíram muito para uma sofisticação do uso do remix. Se compararmos a abertura do filme Carmen Jones (1954) com a última abertura que ele produziu, para o filme Casino (1995), percebe-se uma nítida diferença na complexidade das composições e na quantidade de elementos sobrepostos ao mesmo tempo.

A abertura do filme Casino (figura 8), que Saul Bass produziu em parceria com sua esposa Elaine Makatura, começa com um fundo preto com textos brancos, primeiro o nome das produtoras e depois a sentença "Adapted from a true story" seguido do numeral indicando o ano de 1983 - os textos nesse momento já apresentam ao espectador, portanto, informações relevantes para a trama do filme. Em seguida vemos a protagonista Sam, interpretada por Robert de Niro, saindo de uma casa, entrando em um carro e, assim que o carro é ligado, acontece uma explosão em que as chamas tomam conta de todo o quadro. Nessa sequência de imagens de fogo é sobreposta à personagem principal sendo arremessada pelos ares e, sobre esses dois elementos ainda são adicionados textos na cor branca. Nesse momento, está combinado uma série de elementos concomitantes, a personagem aparece "recortada" como se estivesse realmente voando através do fogo e sobre estes dois é acrescentado o texto escrito. Podese notar a combinação de elementos da mesma mídia com tratamentos diferentes (imagens em movimento do fogo e da personagem) somados a um elemento de outra mídia, o texto escrito. Durante toda a abertura as composições têm essa mesma configuração, imagens em movimento combinadas com sobreposição de textos escritos, na maioria das vezes estáticos.
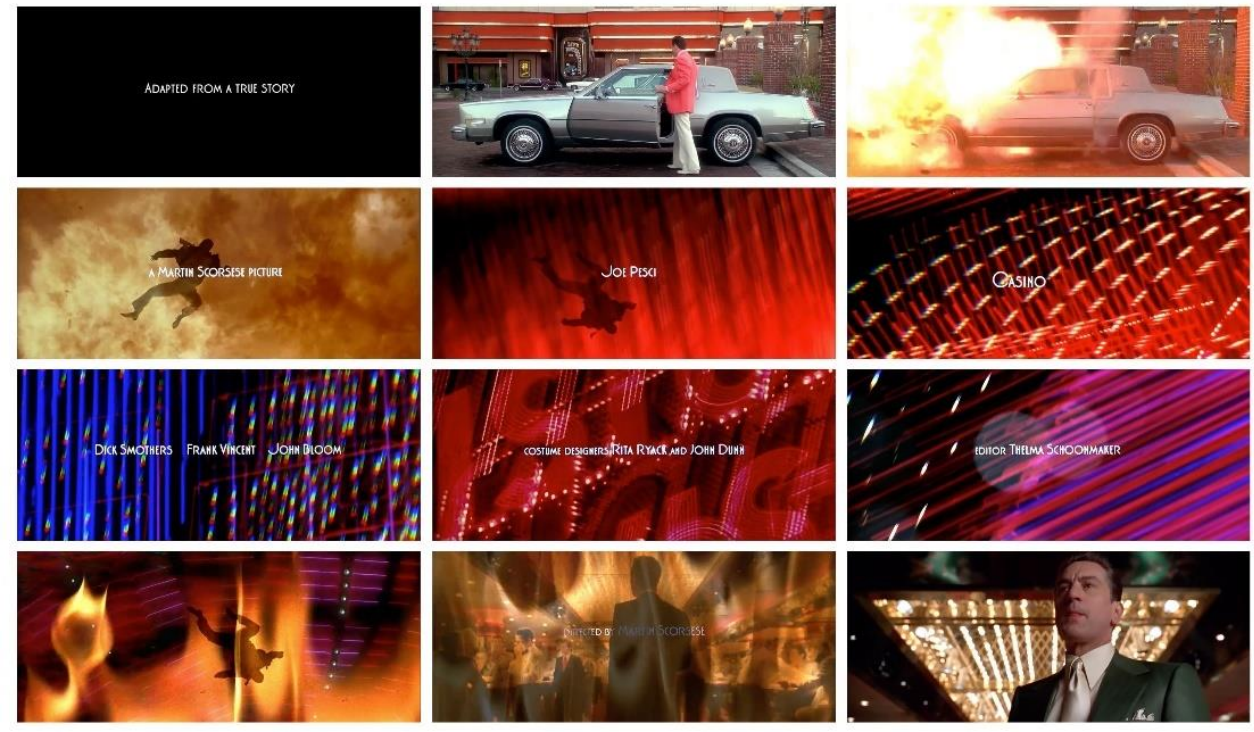

Figura 8: Sequência cronológica de doze fotogramas da abertura do filme realizada por Saul Bass.

Fonte: Casino (1995), direção de Martin Scorsese.

A imagem de fogo em seguida se "transforma" em luzes de luminosos de Las Vegas, primeiro vermelhas como as chamas e depois em diversas tonalidades, apresentando um tipo de evolução cromática. A quantidade de imagens em movimento compostas ao mesmo tempo também varia, chegando a tal ponto que fica difícil determinar quantos trechos são utilizados em cada sequência. Ao final, novamente é inserido a personagem principal "recortada" sobre imagens de luminosos em movimento que em seguida se "transformam" em chamas finalizando os créditos com o nome do diretor. Logo depois a personagem principal está dentro de um cassino e a história começa a ser contada. 
Toda a sequência é, portanto, um exemplo de remixabilidade em que vários elementos vão sendo combinados e se relacionando de diversas maneiras. Além disso, a própria estrutura da abertura também pode ser entendida como remix, pois não existe um ponto que divida a produção entre abertura e filme, já que a própria narrativa começa nos créditos iniciais.

Nesta produção de Saul Bass feita na década de 1990 pode-se notar como as tecnologias digitais potencializaram o remix. Em suas primeiras obras na década de 1950 percebe-se que o número de elementos combinados de maneira simultânea é significativamente menor, provavelmente por questões técnicas que limitavam mesclar diversos elementos em movimento e/ou opções estéticas mais próximas de certas tendências minimalistas e construtivistas.

\section{Considerações finais}

Ao relacionar os estudos feitos por Manovich (2005) a respeito da lógica da remixabilidade com os trabalhos feitos para o cinema do designer gráfico Saul Bass, pode-se notar como a tecnologia digital pode atuar de forma estrutural na concepção e realização de uma (meta) produção audiovisual. Em suas primeiras aberturas de filme, feitas na década de 1950, se consegue determinar de maneira clara o número de elementos que são combinados ao mesmo tempo na tela, o que já não ocorre em sua última produção para o cinema. Trata-se de uma técnica de escritura múltipla que define uma estética do excesso e da instabilidade, na qual o imbricamento dos elementos exige uma leitura sinestésica. Assim:

\footnotetext{
"A multiplicidade praticada em trabalhos como esse nos coloca cara a cara com o que se convencionou chamar de segundo barroco ou neobarroco, tendência geral da arte contemporânea caracterizada pela recusa das formas unitárias ou sistemáticas e pela aceitação deliberada da pluridimensionalidade, da instabilidade e da mutabilidade como categorias produtivas no universo da cultura" (MACHADO, 1997: 239).
}

Com essa análise pode-se apontar também que os créditos de abertura produzidos por Saul Bass compartilham o mesmo conceito do remixabilidade, combinando mídias diferentes em um ambiente comum, gerando novas imagens em movimento com sons e textos escritos de maneira a obter um resultado diferente dos elementos iniciais quando olhados separadamente.

\section{Referências}

DIAMOND, S. Quintessence. Art history shake \& bake. Disponível em: <http://www.horizonzero.ca/textsite/remix.php?is=8\&file=1\&tlang=0>. 2003. Acesso em: 05 jun 2015.

HASKIN, P.; BASS, S. 'Can you make a title?': Interview with Saul Bass. Film Quarterly, vol 50, pp. 10-17. Oakland: University of California Press, 1996.

MACHADO, A. Pré-cinemas \& pós-cinemas. Campinas: Papirus, 1997.

MANOVICH, L. Software takes command. New York: Bloomsbury Academic, 2008.

Understanding hybrid media. 2007. Disponível em: <http://manovich.net/index.php/projects/understanding-hybrid-media>. 2007. Acesso em: 19 jun 2015.

Remixability and modularity. 2005. Disponível em: <http://manovich.net/index.php/projects/remixability-and-modularity>. 2005. Acesso em: 12 jun 2015. 
NAVAS, E. Regressive and reflexive mashups in sampling culture. Disponível em: <http://remixtheory.net/?p=444>. 2010. Acesso em: 25 mai 2015.

SANTAELLA, L. Linguagens Líquidas na Era da Mobilidade. São Paulo: Paulus, 2007.

WOOLMANN, M. Motion design: motion graphics for television, music video, cinema and digital interfaces. Hove: RotoVision, 2004. 